\title{
Minireview
}

\section{Should women under 50 be screened for breast cancer?}

\author{
S Moss*,1 \\ 'Institute of Cancer Research Cancer Screening, Evaluation Unit Block D, 15 Cotswold Road, Suuton, Surrey SM52 5NG, UK
}

\begin{abstract}
Despite some controversy in recent years, the majority of experts agree on the evidence for effectiveness of breast screening by mammography for women aged 50 years and above, but for those under 50 years, the picture is much less clear. However, the issue remains of importance both to policy makers and to individual women; although the incidence of breast cancer is lower at younger ages, the life years lost due to cancers diagnosed below 50 years amount to a third of all those lost due to the disease. British Journal of Cancer (2004) 91, 4I3-4I7. doi: I0.1038/sj.bjc.6601966 www.bjcancer.com

Published online 22 June 2004
\end{abstract}

(c) 2004 Cancer Research UK

Keywords: breast cancer; screening; mammography

This article summarises the current position in different countries, and reviews the most recent evidence on effectiveness of screening women below 50 years from randomised trials. It has not been conducted as a systematic review or meta-analysis, of which a number have been performed. It also addresses the range of potential disadvantages of screening with particular reference to this age group.

\section{CURRENT SCREENING GUIDELINES}

The uncertainty is reflected in the variation in current guidelines among countries for screening women below 50 years for breast cancer. A summary of guidelines used in 22 countries, from a survey conducted in 1995 by the International Breast Screening Network (Shapiro et al, 1998), reported that while a majority of countries or pilot projects had a lower age limit of 50 years, a number involved a lower limit of 40 years, although in countries such as Sweden and Australia policy can vary by county or state. Japan, which does not use mammography, reported a lower age limit of 30 years. In Sweden, the recommended screening interval is 1.5 years for women aged $40-49$ years compared with 2 years for those aged 50 years and above. In the US, the recommendation (updated in February 2002) from the US Preventive Services Task Force is for 'screening mammography with or without clinical breast examination' (CBE) every 1 or 2 years for women aged 40 years and above (US Preventive Services Task Force, 2002). The age range was extended below 50 years despite the finding that 'the strongest evidence of benefit and reduced mortality is among women aged 50-69 years'. The US National Cancer Institute continues to recommend mammography for women in their 40 s and older, while the American Cancer Society recommends 'yearly mammograms' (plus CBE) starting at 40 years (Smith et al, 2003). In 2001, the Canadian Task Force on Preventive Health Care concluded that 'upon reaching the age of 40 years, Canadian women should be informed of the potential benefits and risks of

*Correspondence: Dr S Moss; E-mail: sue.moss@icr.ac.uk

Received 20 November 2003; revised 12 March 2004; accepted 23 March 2004; published online 22 June 2004 screening mammography and assisted in deciding at what age they wish to initiate the manoeuvre' (Ringash, 2001).

The IARC Handbook of Cancer Prevention on breast cancer screening, published in 2002, concluded that the marginal costeffectiveness of expanding a programme to younger women (aged 40-49 years) greatly depends on its effect on reducing breast cancer mortality as estimated from randomised controlled trials, 'and that it is likely to be more cost-effective to make other changes'.

\section{THE EFFECTIVENESS OF SCREENING IN YOUNGER WOMEN}

\section{Evidence from randomised trials}

Of the eight randomised trials, which have so far reported mortality results and included women aged $40-49$ years at entry, only one (Miller et al, 1992) was designed specifically to study the effectiveness of screening in this age group. The remainder included cohorts of women between 40 or 45 and 64 years or older at entry. The relevant trials are summarised in Table 1 (the trial in Malmo, which included two cohorts, being included as two separate entries).

There is evidence accumulating from these trials of a possible benefit of screening in women under the age of 50 years. A number of meta-analyses of these trials have been performed (Smart et al, 1995). The most recent of these, published in 1997, included an average follow-up time of 12.7 years and estimated a significant $18 \%$ reduction in mortality from breast cancer among women aged 40-49 years at entry, invited to screening mammography (RR 0.82, 95\% CI 0.71-0.95) (Hendrick et al, 1997). An analysis restricted to the five Swedish trials estimated a $29 \%$ mortality reduction among women invited to screening (RR $0.71,95 \% 0.57-0.89$ ).

The significant benefit seen in this latest meta-analysis is due primarily to updated results from trials in Gothenburg and Malmo. The Gothenburg trial began in 1983/1984, and included approximately 26000 women aged 39-49 years, of whom 11724 were randomised to an intervention arm invited for screening by mammography every 18 months. Those in the control arm were 
Table I Randomised trials of breast screening

\begin{tabular}{|c|c|c|c|c|c|c|}
\hline Study & $\begin{array}{l}\text { Screening } \\
\text { interval } \\
\text { (months) }\end{array}$ & CBE included & Study & $\begin{array}{l}\text { Length of } \\
\text { follow-up } \\
\text { (years) }\end{array}$ & $\begin{array}{c}\text { Age range } \\
\text { at entry }\end{array}$ & $\operatorname{RR}(95 \% \mathrm{CI})$ \\
\hline HIP (Shapiro et al, 1988) & 12 & Yes & $1963-1966$ & 18 & $40-59$ & $0.77(0.53,1.11)$ \\
\hline Ostergotland (Nystrom et al, 2002) & 24 & No & $1978-198 \mid$ & 17 & $38-49$ & $1.05(0.64,1.71)$ \\
\hline Kopparberg (Tabar et al, 2000) & 24 & No & $1976-1978$ & 17 & $40-49$ & $0.76(0.42,1.40)$ \\
\hline Malmo I (Nystrom et al, 2002) & $18-24$ & No & $1976-1978$ & 19 & $45-49$ & $0.74(0.44,1.25)$ \\
\hline Malmo II (Nystrom et al, 2002) & $18-24$ & No & $1978-1990$ & 12.7 & $43-49$ & $0.64(0.45,0.89)$ \\
\hline Gothenburg (Nystrom et al, 2002) & 18 & No & $1982-1984$ & 13 & $39-49$ & $0.58(0.35,0.96)$ \\
\hline Stockholm (Nystrom et al, 2002) & 28 & No & $1981-1983$ & 15 & $39-49$ & $1.52(0.80,2.88)$ \\
\hline Edinburgh (Alexander et al, 1999) & 24 & Yes (annual) & $1978-198 \mid$ & 14 & $45-49$ & $0.83(0.54,1.27)$ \\
\hline NBSS $^{a}$ | (Miller et al, 2002) & 12 & Yes & $1980-1985$ & 12 & $40-49$ & $0.97(0.74,1.27)$ \\
\hline
\end{tabular}

a Mammography+CBE vs $\mathrm{CBE}$ alone. $\mathrm{RR}=$ relative risk; $95 \% \mathrm{Cl}=95 \%$ confidence interval.

invited at the time of the fifth screen of the intervention arm (6-7 years after the date of entry). Owing to the small sample size, a significant reduction was not apparent until 12 years of follow-up, at which time a $45 \%$ reduction in mortality from breast cancer was observed in the intervention arm (RR 0.55, 95\% CI $0.31-0.96$ ) (Bjurstam et al, 1997).

The Malmo trial contained approximately 8000 women under 50 years at entry in the initial cohort randomised in $1977-1978$, and a further 17000 women randomised at age 45-48 years between 1978 and 1990. Pooling the two cohorts, there was a statistically significant reduction in breast cancer mortality in the intervention arm at 12 years of follow-up (RR $0.64,95 \%$ CI $0.45-0.89$ ) (Andersson and Janzon, 1997).

An updated overview of the five Swedish studies, published in 2002, did not include the Kopparberg part of the Two-County trial, but did include a continuation of the Malmo trial (Nystrom et al, 2002). In this overview, the median follow-up time was 15.8 years; there was a $20 \%$ reduction in women aged $40-49$ years at entry (RR $0.80,95 \%$ CI $0.63-1.01$ ), and an analysis by 5 year age groups found no significant heterogeneity.

The Canadian National Breast Screening Study 1 was designed to evaluate the efficacy of the combination of annual mammography, physical examination and the teaching of breast self-examination in reducing the rate of death from breast cancer among women aged 40-49 years at entry. Between 1980 and 1985, the trial randomised 50430 women aged $40-49$ years to an arm offered annual mammography and physical examination (MP), or to an arm offered usual care (UC) after an initial physical examination. After a mean of 8.5 years of follow-up, there was a nonsignificant $3.6 \%$ increase in breast cancer mortality in the MP group (RR 1.36, $95 \%$ CI $0.84-2.21$ ); at a mean of 13 years follow-up the rate ratio was 0.97 (95\% CI $0.74-1.27)$. An adjustment taking account of mammography done outside the study yielded a rate ratio of 1.06 (95\% CI 0.80-1.40) (Miller et al, 2002).

This trial made use of a volunteer population, which may not be representative of the general population, and there has been debate over the quality of mammography, and over the effect of the initial examination and education in the control arm. A major drawback of the study has been the lack of statistical power, in part due to lower than anticipated mortality in the control arm, with the result that even after 13 years the confidence intervals are wide (Kopans et al, 1994).

\section{Interpretation of results}

The interpretation of the various trial results has been widely debated. Differences between the stage or size distribution of cancers in the control arms have been cited as explaining observed differences in benefit between trials (Narod, 1997), but despite differences in study design there is no statistically significant heterogeneity (Hendrick et al, 1997). Since the effect of screening on mortality from breast cancer takes a number of years to become apparent, and all the trials have invited women for routine rescreening at intervals ranging from 18 to 33 months, it is difficult to separate the effect of screening examinations, which took place above and below 50 years. Analyses by age at diagnosis are complicated by the effect of lead-time, the length of time by which diagnosis has been advanced for screen-detected cancers which will lower the age at diagnosis.

The MISCAN simulation model has been used to estimate that $70 \%$ of the mortality reduction observed in the Swedish trials in women aged 40-49 years at entry was a result of screening these women after they reached 50 years (de Koning et al, 1995), based on a comparison of predicted with observed results. However, the alternative assumption that screening under 50 years has the same effect as that in older women could not be excluded on the basis of this analysis.

This analysis was based on the observed breast cancer mortality reduction of $10 \%$ in women aged $40-49$ years reported at that time; with longer follow-up, the observed reduction is larger, and further analyses are being conducted in order to update these estimates (de Koning, personal communication).

Reasons for a possible lesser effect of screening in younger women include lower sensitivity of mammography due to a higher prevalence of dense tissue, and a tendency for tumours in young women to be faster growing, implying a need for more frequent screening (Tabar et al, 1995).

The results of a meta-analysis (which also included one casecontrol study) suggested that the summary relative risk of mortality from breast cancer in women aged 40-49 years invited for screening compared with those who were not was lower for studies using two view mammography, and for studies with longer follow-up (Kerlikowske et al, 1995).

It appears likely that there will be a benefit in terms of reduced mortality from breast cancer associated with screening below 50 years, and that frequent (e.g. probably annual) screening will be necessary to achieve this. However, the size of the benefit and the age(s) at which screening should be performed are as yet unknown. It is likely that any changes in the effectiveness of screening with increasing age occur gradually, and the choice of age 50 years for subgroup analyses is arbitrary (Kopans, 1998), although this could be viewed as a surrogate for age at menopause.

\section{Research in progress}

A trial in progress in the UK has been designed specifically to address the question of whether offering screening by mammography from 40 years is effective in reducing mortality from breast cancer, compared with the current national policy of inviting women from the age of 50 years (Moss, 1999). A total of 160000 women aged 40-41 years have been randomised in the ratio $2: 1$ to a control arm or an intervention arm. Women in the latter are 
offered annual mammography, until 48 years by two views at first screen, and single view at subsequent screens unless indicated otherwise. Women in the control arm receive usual medical care, and those in both arms will receive their first invitation to screening as part of the national programme between 50 and 52 years. The trial began in 1991 and includes 23 centres, all of which are existing NHS breast screening units. The trial is powered to detect a $20 \%$ reduction in breast cancer mortality at 10 years of follow-up. Meanwhile, surrogate outcome measures in terms of pathology characteristics are being considered (Anderson et al, 2000).

\section{COSTS OF SCREENING}

The financial costs of mammography include those of screening mammography, and further assessment and treatment costs, as well as organisational costs for organised programmes. Screening will also impact on treatment costs. The frequency of screening will affect the cost across a given age range, and most comparisons of cost-effectiveness have assumed a shorter screening interval (1218 months) below 50 years. However, the results of such comparisons will vary according to the estimate of effectiveness used. De Haes et al (1991) concluded that it would be more costeffective to shorten the screening interval for women aged 50-70 years than to include 2 yearly screening for women aged 40-49 years, based on the $8 \%$ mortality reduction then observed in the Swedish Two Counties Study in women under 50 years. An analysis in 1995 by Lindfors and Rosenquist (1995), using a baseline estimate of mortality reduction for women aged 40-49 years of $4 \%$ with biennial and $23 \%$ with annual mammography, found that including women aged 40-49 years increased the marginal cost per life year saved, but by less than some alternative strategies. Salzmann et al (1997) assumed a $16 \%$ reduction in breast cancer mortality starting at 50 years for women who begin screening at 40 years and found that the cost-effectiveness of mammography in women aged 40-49 years was about five times that in older women.

\section{ADVERSE EFFECTS OF SCREENING}

In common with all screening tests, there are risks or disadvantages associated with mammography, which need to be weighed against any beneficial effect. Information on the adverse effects of screening is essential to enable decisions to be reached by policy makers on whether screening should be offered, and by women on an individual basis on whether or not to attend.

\section{False-positive results}

Referral for further assessment of women who are subsequently found to be free of cancer is one disadvantage of screening, which will have a cost in terms of resources (Lidbrink et al, 1996), and to the women referred. While attempts can be made to keep referral rates low, there is a 'trade off between specificity and sensitivity, since if referral rates are too low, then the cancer detection rates may also be low. Within the NHS breast screening programme, referral rates tend to decrease with age, while cancer detection rates increase in line with underlying incidence, with the result that the positive predictive value of referral for assessment (i.e. the probability that a woman referred will be found to have breast cancer) is likely to be lower below 50 years. The cumulative risk of a false-positive test (in women aged 40-69 years) has been estimated in one US study to be $49 \%$ after 10 mammograms (Elmore et al, 1998).

A number of studies have looked at the psychological effects of the screening process on women, both for those screened as normal and those referred for further assessment. Routine attendance for screening in general seems to have little effect, although some subgroups experience distress or increased anxiety (Walker et al, 1994). The most significant effects are observed in women referred for further assessment with false-positive results. While most studies have found increased anxiety in those women to be fairly short-lived (Cockburn et al, 1994; Ellman and Thomas, 1995; Lampic et al, 2001), some have reported long-term effects (Lerman et al, 1991). However a false-positive result does not appear to deter women from subsequent attendance for screening (Lerman et al, 1991; Lightfoot et al, 1994). Anxiety is likely to be minimised by the provision of appropriate information and by reducing the time between initial screen and assessment. Timely reporting of results may also reduce anxiety of the effects associated with earlier stages in the screening process.

\section{Exposure to radiation}

The possible harmful effect of radiation resulting from mammography in this age group has been widely debated (Law, 1995; Feig and Hendrick, 1997; Young, 2001). Estimates of breast cancer risk from low-dose radiation exposure are, by necessity, extrapolated from studies of populations exposed to much higher doses, for example atomic bomb survivors, or those receiving medical radiation treatment, and these studies have suggested a greater effect at lower ages of exposure. The estimated risk associated with radiation will depend on whether a linear or quadratic dose response model is chosen, and on whether an additive or relative risk model is used. The average radiation dose for mammography has reduced considerably over the past $15-20$ years, and most recent studies have estimated that the benefit of screening is likely to outweigh the risk even in younger women (Law and Faulkner, 2001). Estimates of the average received dose in the UK Age trial are of $2.5 \mathrm{mGy}$ per oblique film and $2.0 \mathrm{mGy}$ per craniocaudal film (Young, 2001); in this study, age was not found to be a significant factor affecting the dose to screened women aged above or below 50 years. A small proportion of women will receive higher doses for reasons such as large breasts requiring more than one film per view.

\section{Overdiagnosis}

Another concern about screening is the possibility of over diagnosis, by the detection of lesions which would otherwise not have presented clinically during a woman's lifetime. In the case of breast screening, there is particular uncertainty over the natural history of ductal carcinoma in situ (DCIS), which is infrequently diagnosed in the absence of screening. In the Swedish Two Counties randomised controlled trial, there was most evidence of over diagnosis in women below 50 years (Tabar et al, 1992); however, in that trial, the rate of detection of DCIS was comparatively low. In the NHS breast screening programme, $4 \%$ of cancers detected by screening in 2000/2001 in women aged above 50 years were in situ (NHS Breast Screening Programme Annual Review, 2002). The benefit of detecting and treating DCIS remains an area of debate. A study in the UK found that the majority of DCIS detected by screening was high-grade (Evans et al, 2001), and will, therefore, have a high probability of progression to invasive cancer, but others have argued that progression rates may be much lower (Jatoi and Baum, 1995; Baum, 1996). The IARC handbook concludes that studies are required on the natural history of DCIS, and on the impact of detection and treatment of DCIS on the incidence of invasive cancers.

\section{Screening in high-risk women}

Of particular concern in many settings is the management of women at increased risk of breast cancer due to family history of the disease. It is estimated that such cases may account for between 5 and $10 \%$ of all cases (Eeles, 1999), and such women will be at increased risk from a young age. It has been estimated that most of 
416

the excess risk of familial breast cancer occurs before 50 years (Houlston et al, 1992) and it is generally recommended that screening start 5-10 years before the earliest age at diagnosis of affected family members.

Clearly if screening is effective in this age group, then the absolute benefit in this subgroup will be greater, as will the costeffectiveness. Nevertheless, there is no more evidence for effectiveness in high-risk women than in the general population.

In the UK, two studies are in progress to assess the effect of screening in high-risk women. A randomised controlled trial is comparing the sensitivity of mammography and magnetic resonance imaging (MRI) in high-risk women identified from genetics clinics (The UK MRI Breast Screening Study Advisory Group, 2000). Magnetic resonance imaging does not involve the use of ionising radiation, and hence may be of particular relevance for screening at young ages. However, studies to date have suggested high sensitivity but possibly low specificity. The cost of the technique at present is such that its use is only under consideration for women at high risk. A second study is evaluating mammographic surveillance in women under 50 years with a family history of breast cancer, with the aim of estimating the difference in breast cancer mortality in screened compared with unscreened women, and estimating the cost-effectiveness of regular mammography in this group (MacKay et al, 2001).

Ultrasound has also been considered as a screening modality for high-risk women, although there are doubts about both sensitivity and specificity (Teh and Wilson, 1998). One recent study concluded that MRI is likely to be superior as a screening method for such women (Warner et al, 2001).

The increased radiation risk in these women will be affected by the choice of model (additive or relative risk). It is possible that

\section{REFERENCES}

Alexander FE, Anderson TJ, Brown HK, Forrest AP, Hepburn W, Kirkpatrick AE, Muir BB, Prescott RJ, Smith A (1999) 14 years of follow-up from the Edinburgh randomised trial of breast-cancer screening. Lancet 353: $1903-1908$

Anderson TJ, Alexander FE, Lamb J, Smith A, Forrest AP (2000) Pathology characteristics that optimize outcome prediction of a breast screening trial. Br J Cancer 83: 487-492

Andersson I, Janzon L (1997) Reduced breast cancer mortality in women under age 50: updated results from the Malmo Mammographic Screening Program. J Natl Cancer Inst Monogr 22: 63-67

Baines CJ (2003) Mammography screening: are women really giving informed consent? J Natl Cancer Inst 95: 1508-1511

Baum M (1996) The breast screening controversy. Eur J Cancer 32A: $9-11$

Bjurstam N, Bjorneld L, Duffy SW, Smith TC, Cahlin E, Eriksson O, Hafstrom LO, Lingaas H, Mattsson J, Persson S, Rudenstam C-M, SaveSoderbergh J (1997) The Gothenburg Breast Screening Trial: First Results on Mortality, Incidence, and Mode of Detection for Women Ages 39-49 Years at Randomization. Cancer 80: 2091-2099

Cockburn J, Staples M, Hurley SF, De Luise T (1994) Psychological consequences of screening mammography. J Med Screening 1: 7-12

de Haes JCJM, de Koning HJ, van Oortmarssen GJ, van Agt HME, de Bruyn AE, van der Maas PJ (1991) The impact of a breast cancer screening programme on quality-adjusted life-years. Int J Cancer 49: 538-544

de Koning HJ, Boer R, Warmerdam PG, Beemsterboer PMM, van der Maas PJ (1995) Quantitative interpretation of age-specific mortality reductions from the Swedish breast cancer-screening trials. J Natl Cancer Inst 87: $1217-1223$

Eeles RA (1999) Screening for hereditary cancer and genetic testing, epitomised by breast cancer. Eur J Cancer 35: 1954-1962

Ellman R, Thomas BA (1995) Is psychological well being impaired in long term survivors of breast cancer? J Med Screening 2: 5-9

Elmore J, Wells C, Howard D (1998) Does diagnostic accuracy in mammography depend on radiologists' experience? J Women Health 7: $443-449$ some women genetically predisposed to breast cancer may also have increased sensitivity to radiation, and if screened frequently from a young age will also have increased total exposure. An example is ataxia telangiectasia (AT), an inherited autosomal recessive disease. Women who are AT gene carriers are also at increased risk of developing breast cancer; however, there remains debate as to whether this risk is increased by exposure to ionising radiation (Swift et al, 1991; Wagner, 1992).

\section{CONCLUSIONS}

Until more information is available, it is difficult to inform either policy makers (in terms of potential changes to national screening programmes) or individual women on the balance between costs and effectiveness of screening below 50 years. It has recently been suggested, on the basis of age-specific incidence rates, that screening in the UK should begin at 47 years (Sasieni and Cuzick, 2003), but the effect of such a policy in terms of mortality reduction is not clear. For example, a number of the randomised trials have observed a lesser effect in women aged 50-54 years at entry.

For individual women, full information on the possible benefits and harmful effects of screening are essential to enable an 'informed choice' to be made and the need for accurate and understandable information has been emphasised recently (Baines, 2003; Thornton et al, 2003). Only once further information on the effectiveness of screening below 50 years is available, can the costeffectiveness of any change in policy can be estimated. Decisions on national policy will then depend on comparing cost-effectiveness with other policy options.
Evans AJ, Pinder SE, Ellis IO, Wilson ARM (2001) Screen detected ductal carcinoma in situ (DCIS): overdiagnosis or an obligate precursor of invasive disease? J Med Screening 8: $149-151$

Feig SA, Hendrick RE (1997) Radiation risk from screening mammography of women aged 40-49 years. J Natl Cancer Inst Monogr 22: $119-124$

Hendrick RE, Smith RA, Rutledge JH, Smart CR (1997) Benefit of screening mammography in women aged 40-49; a new metaanalysis of randomized controlled trials. Monogr Natl Cancer Inst 22: $87-92$

Houlston RS, McCarter E, Parbhoo S, Scurr JH, Slack J (1992) Family history and risk of breast cancer. J Med Genet 29: $154-157$

Jatoi I, Baum M (1995) Mammographically detected ductal carcinoma in situ: are we overdiagnosing breast cancer? Surgery 118: $118-120$

Kerlikowske K, Grady D, Rubin SM, Sandrock C, Ernster VL (1995) Efficacy of screening mammography. A meta-analysis. JAMA 273: $149-154$

Kopans DB (1998) The mammography screening controversy. Cancer J Sci Am 4: $22-24$

Kopans DB, Halpern E, Hulka CA (1994) Statistical power in breast cancer screening trials and mortality reduction among women 40-49 years of age with particular emphasis on the National Breast Screening Study of Canada. Cancer 74: 1196-1216

Lampic C, Thurfjell E, Bergh J, Sjoden P-O (2001) Short- and long-term anxiety and depression in women recalled after breast cancer screening. Eur J Cancer 37: 463-469

Law J, Faulkner K. (2001) Cancers detected and induced, and associated risk and benefit, in a breast screening programme. Br J Radiol 74: $1121-1127$

Law J (1995) Risk and benefit associated with radiation dose in breast screening programmes - an update. $\mathrm{Br}$ J Radiol 68: 870-876

Lerman C, Trock B, Rimer BK, Boyce A (1991) Psychological and behavioural implications of abnormal mammograms. American College of Physicians - Am Soc Int Med 114: 657-661

Lidbrink E, Elfving J, Frisell J, Jonsson E (1996) Neglected aspects of false positive findings of mammography in breast cancer screening: 
analysis of false positive cases from the Stockholm trial. $B M J$ 312: $273-276$

Lightfoot N, Steggles S, Wilkinson D, Bissett R, Bakker D, Darlington G, Erola K, Miller D (1994) The short-term psychological impact of organised breast cancer screening. Curr Oncol 1: 206-211

Lindfors KK, Rosenquist CJ (1995) The cost-effectiveness of mammographic screening strategies. JAMA 274: 881-884

MacKay J, Rogers C, Fielder H, Blamey R, MacMillan D, Boggis CR, Brown J, Pharoah PD, Moss S, Day NE, Myles J, Austoker J, Gray J, Cuzick J, Duffy SW (2001) Development of a protocol for evaluation of mammographic surveillance services in women under 50 with a family history of breast cancer. J Epidemiol Biostat 6: $365-369$

Miller AB, Baines CJ, To T, Wall C (1992) Canadian National Breast Screening Study: 1. Breast cancer detection and death rates among women aged 40 to 49 years. Can Med Assoc J 147: 1459-1476

Miller AB, To T, Baines CJ, Wall C (2002) The Canadian National Breast Screening Study-1: breast cancer mortality after 11 to 16 years of followup. Ann Intern Med 137: E-305-E-315

Moss S, for the Trial Steering Group (1999) A trial to study the effect on breast cancer mortality of annual mammographic screening in women starting at age 40. J Med Screening 6: 144-148

Narod S (1997) On being the right size: a reappraisal of mammography trials in Canada and Sweden. Lancet 349: 1846

Nystrom L, Andersson I, Bjurstam N, Frisell J, Nordenskjold B (2002) Longterm effects of mammography screening: updated overview of the Swedish randomised trials. Lancet 359: 909-919

Ringash J (2001) Preventive health care, 2001 update: screening mammography among women aged $40-49$ years at average risk of breast cancer. Can Med Assoc J 164: 469-476

Salzmann P, Kerlikowske K, Phillips K (1997) Cost-effectiveness of extending screening mammography guidelines to include women 40 to 49 years of age. Arch Intern Med 127: 955-965

Sasieni P, Cuzick J (2003) The UK breast-screening programme should start at age 47 years. Lancet 362: 247

Shapiro S, Coleman EA, Broeders M, Codd M, de Koning H, Fracheboud J, Moss S, Paci E, Stachenko S, Ballard-Barbash R (1998) For the International Breast Cancer Screening Network (IBSN) and the European Network of Pilot Projects for Breast Cancer Screening. Breast cancer screening programmes in 22 countries: current policies, administration and guidelines. Int J Epidemiol 27: 735-742

Shapiro S, Venet W, Strax P, Venet L (1988) Periodic Screening for Breast Cancer. Baltimore \& London: Johns Hopkins University Press
Smart CR, Hendrick RE, Rutledge JHI, Smith RA (1995) Benefit of mammography screening in women ages 40 to 49 years. Current evidence from randomized controlled trials. Cancer 75: 1619-1626

Smith A, Saslow D, Sawyer K, Burke W, Costanza M, Evans III W, Foster Jr RS, Hendrick E, Eyre H, Sener S (2003) American Cancer Society guidelines for breast cancer screening: update 2003. Can J Clin 53: $141-169$

Swift M, Morrell D, Massey RB, Chase CI (1991) Incidence of cancer in 161 families affected by ataxia-telangiectasia. N Engl J Med 325: 1831-1836

Tabar L, Fagerberg G, Chen HH, Duffy SW, Gad A (1995) Screening for breast cancer in women aged under 50: mode of detection, incidence, fatality and histology. J Med Screening 2: 94-98

Tabar L, Fagerberg G, Duffy SW, Day NE, Gad A, Grontoft O (1992) Update of the Swedish two-county program of mammographic screening for breast cancer. Radiol Clin North Am 30: 187-210

Tabar L, Vitak B, Chen HH, Duffy SW, Yen MF, Chiang CF, Krusemo UB, Tot T, Smith RA (2000) The Swedish Two-County Trial twenty years later. Updated mortality results and new insights from long-term followup. Radiol Clin North Am 38: 625-651

Teh W, Wilson ARM (1998) The role of ultrasound in breast cancer screening. A consensus statement by the European Group for Breast Cancer Screening. Eur J Cancer 34: 449-450

The UK MRI Breast Screening Study Advisory Group (2000) (Brown J, Coulthard A, Dixon AK, Dixon JM, Easton DF, Eeles RA, Evans DGR, Moss SM) Protocol for a national multi-centre study of magnetic resonance imaging screening in women at genetic risk of breast cancer. Breast 9: 78-82

Thornton H, Edwards A, Baum M (2003) Women need better information about routine mammography. BMJ 327: $101-103$

U.S. Preventive Services Task Force (2002) Screening for breast cancer: recommendations and rationale. Ann Intern Med 137: 344-346

Wagner LK (1992) To the Editor. N Engl J Med 326: 1358

Walker L, Cordiner C, Gilbert F, Needham G, Deans H, Affleck I, Hood D, Mathieson D, Ah-See A, Eremin O (1994) How distressing is attendance for routine breast screening? Psy-Oncol 3: 299-304

Warner E, Plewes DB, Shumak RS, Catzavelos GC, Di Prospero LS, Yaffe MJ, Goel V, Ramsay E, Chart PL, Cole DE, Taylor GA, Cutrara M, Samuels TH, Murphy JP, Murphy JM, Narod SA (2001) Comparison of breast magnetic resonance imaging, mammography, and ultrasound for surveillance of women at high risk for hereditary breast cancer. J Clin Oncol 19: $3524-3531$

Young KC (2001) Radiation doses in the United Kingdom trial of breast screening in women aged 40 to 48 . Br J Radiol 75: $362-370$ 